\title{
Inhibiting ROS-TFEB-Dependent
} Autophagy Enhances Salidroside-Induced Apoptosis in Human Chondrosarcoma Cells

\author{
Wei Zenga,b Tao Xiao Anlie Cai ${ }^{\mathrm{b}}$ Weiliang Cai ${ }^{\mathrm{a}}$ Huanhuan Liu ${ }^{\mathrm{c}}$ Jingling Liu \\ Jie Li $^{\mathrm{b}}$ Miduo Tan ${ }^{\mathrm{d}}$ Li Xie $^{\mathrm{e}}$ Ying Liu ${ }^{\mathrm{b}}$ Xiangcheng Yang ${ }^{\mathrm{b}}$ Yi Long ${ }^{\mathrm{b}}$
}

\begin{abstract}
aDepartment of Orthopedics Surgery, Second Xiangya Hospital of Central South University, Changsha, Hunan, bepartment of Orthopedics Surgery, Central Hospital of Zhuzhou City and Affiliated Zhuzhou Hospital of Xiangya Medical College of Central South University, Hunan, ' Department of Infectious Diseases, Central Hospital of Zhuzhou City and Affiliated Zhuzhou Hospital of Xiangya Medical College of Central South University, Hunan, dSurgery Department of Galactophore, Central Hospital of Zhuzhou City and Affiliated Zhuzhou Hospital of Xiangya Medical College of Central South University, Hunan, eDepartment of Intergrated traditional Chinese medicine and western medicine, Central Hospital of Zhuzhou City and Affiliated Zhuzhou Hospital of Xiangya Medical College of Central South University, Hunan, People's Republic of China
\end{abstract}

\section{Key Words}

Salidroside • Autophagy • TFEB • Reactive Oxygen Species • Apoptosis • Chondrosarcoma

\begin{abstract}
Background/Aims: Autophagy modulation has been considered a potential therapeutic strategy for human chondrosarcoma, and a previous study indicated that salidroside exhibits significant anti-carcinogenic activity. However, the ability of salidroside to induce autophagy and its role in human chondrosarcoma cell death remains unclear. Methods: We exposed SW1353 cells to different concentrations of salidroside $(0.5,1$ and $2 \mathrm{mM})$ for 24 h. RT-PCR, Western-blotting, Immunocytofluorescence, and Luciferase Reporter Assays were used to evaluate whether salidroside activated the TFEB-dependent autophagy. Results: We show that salidroside induced significant apoptosis in the human chondrosarcoma cell line SW1353. In addition, we demonstrate that salidroside-induced an autophagic response in SW1353 cells, as evidenced by the upregulation of LC3-II and downregulation of P62. Moreover, pharmacological or genetic blocking of autophagy enhanced salidroside -induced apoptosis, indicating the cytoprotective role of autophagy in salidroside-treated SW1353 cells. Salidroside also induced TFEB (Ser142) dephosphorylation, subsequently to activated TFEB nuclear translocation and increase of TFEB reporter activity, which contributed to lysosomal biogenesis and the expression of autophagy-related genes. Importantly, we found that salidroside triggered the generation of ROS in SW1353 cells. Furthermore, NAC, a ROS scavenger, abrogated the effects of salidroside on TFEB-dependent autophagy. Conclusions: These data demonstrate that salidroside increased TFEB-dependent autophagy by activating ROS signaling pathways in human chondrosarcoma cells. These data also suggest that blocking ROS-TFEB-dependent autophagy to enhance the activity of salidroside warrants further attention in treatment of human chondrosarcoma cells.




\section{Cellular Physiology Cell Physiol Biochem 2017;43:1487-1502

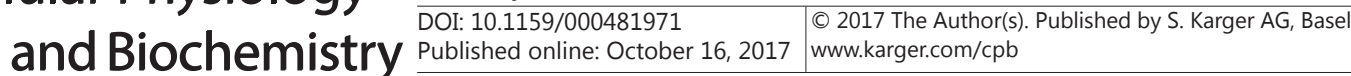 \\ Zeng et al.: Effects of Salidroside on Chondrosarcoma Cancer Cells}

\section{Introduction}

Chondrosarcoma is the second most prevalent (or frequent) general primary tumor in bone [1], and has been identified as an invasive and pathologically diverse malignant tumor with poor disease progression [2]. Although the long-term outcome of patients with highgrade chondrosarcoma who undergo surgery has been improved by the addition of systemic chemotherapy, the efficacy of most neoadjuvant chemotherapy drugs is uncertain, and these drugs are associated with severe side effects [3]. Recently, the application of small molecules or natural compounds isolated from plants has become an attractive strategy due to their high biological activity and safety; thus, these compounds have emerged as a vital type of complementary and alternative medicine. For instance, berberine [4], curcumin [5], and resveratrol [6], which are natural products derived from several medicinal plants abundant in southeast Asia, have been shown to inhibit chondrosarcoma cell growth and cause apoptosis by regulating of several cell cycle regulators and/or developmental signaling pathways.

Salidroside, one of the most potent compounds isolated from the plant Rhodiola rosea, has been suggested to possess anti-inflammatory, anti-proliferative, and anti-oxidant activities in various animal model systems and cell cultures $[7,8]$. This compound has recently attracted considerable attention because of accumulating data demonstrating its strong inhibitory effect on bladder carcinoma, colorectal cancer [9], and breast cancer [10]. However, the potential anticancer properties of salidroside in chondrosarcoma are not well known.

Autophagy is a homeostatic, catabolic degradation process whereby cellular proteins and organelles are engulfed by autophagosomes, digested in lysosomes, and recycled to sustain cellular metabolism [11]. Autophagy can function as a cellular housekeeper by removing damaged organelles and recycling macromolecules; therefore, autophagy can protect cancer cells, particularly during malignant transformation and carcinogenesis [12]. A growing body of evidence indicates that autophagy can help human cancer cells survive by conferring apoptosis resistance, and inhibition of autophagy causes caspase-dependent apoptosis cell death, especially in the presence of other therapies [13, 14]. Understanding the interplay between apoptosis and autophagy in tumors is crucial to identify new targets for cancer therapy and improve the therapeutic efficiency. Thus, the ability of salidroside to increase autophagic activity in human chondrosarcoma cells should be determined because this effect has been hypothesized to significantly reduce treatment efficacy.

Recently, the activation of the basic helix-loop-helix leucine zipper transcription factor TFEB (transcription factor EB) has been shown to be involved in multiple aspects of oncogenesis, including inflammatory responses, cellular differentiation, proliferation, and survival in almost all multi cellular organisms [15]. TFEB is dysregulated in many forms of cancer, including breast cancer, lung cancer, and pancreatic cancer [16-18], and recent studies have suggested a correlation between autophagy and the TFEB pathway in human cancer. Specifically, TFEB initiates an autophagy-lysosomal biogenesis program, which stimulates the overall degradative capacity of cancer cells and plays an important role in cancer biology and clinical behavior $[19,20]$. Importantly, under stress full conditions such as chemotherapy treatment, an intricate interplay between the homeostatic TFEB and autophagy pathways and the apoptotic executive process may occur in cancer cells that will ultimately dictate their fate between cell death or survival.

In the current study, we investigated whether the modulation of autophagy may be used as an adjuvant modality to improve the effects of chemotherapy during chondrosarcoma treatment. We demonstrated that salidroside exerts an antitumor effect and induces autophagy by targeting the ROS-TFEB signaling pathways in SW1353 cells. In addition, inhibiting autophagy enhanced the antitumor activity of salidroside. These findings provide important insights that may aid in the development of novel strategies to enhance the response of cancer cells to salidroside by exploiting the role of autophagy in chondrosarcoma therapy.

\section{KARGER}




\section{Cellular Physiology Cell Physiol Biochem 2017;43:1487-1502 \begin{tabular}{ll|l} 
and Biochemistry Published online: October 16, 2017 & $\begin{array}{l}\text { C } 2017 \text { The Author(s). Published by S. Karger AG, Basel } \\
\text { www.karger.com/cpb }\end{array}$ \\
\hline
\end{tabular}}

Zeng et al.: Effects of Salidroside on Chondrosarcoma Cancer Cells

\section{Materials and Methods:}

\section{Drugs and reagents}

Bafilomycin A1, DCFH-DA, and N-acetyl cysteine (NAC) were purchased from Sigma-Aldrich (St. Louis, MO, USA), Salidroside (purity $>99 \%$ ) was purchased from the National Institute for the Control of Pharmaceutical and Biological Products (Beijing, China).

\section{Cell culture and salidroside treatment}

The human chondrosarcoma cell line SW1353 was purchased from the American Type Culture Collection and cultured in Dulbecco's modified Eagle's medium (DMEM) (Gibco, Carlsbad, CA, USA) supplemented with 10\% fetal bovine serum (FBS) (P30-3302, PAN-Biotech, Germany) in a humidified incubator at $37^{\circ} \mathrm{C}$ with $5 \% \mathrm{CO}_{2}$. The cells were passaged by dissociating them $0.25 \%$ trypsin-EDTA solution (Gibco) for 1-2 min after they had grown to $80-90 \%$ confluency. Salidroside was diluted in cell culture medium to a final concentration of $0.5,1$ or $2 \mathrm{mM}$, and cells were cultured in salidroside for $24 \mathrm{~h}$.

The Sprague-Dawley rats used in this study were purchased from the Central South University. This study was approved by the Animal Care and Use Committee of Central South University and was carried out in accordance with the Guide for the Care and Use of Laboratory Animals by the National Research Council. Cranial OBs were obtained from 18-19-day-old Sprague-Dawley rat fetuses. The calvarias were incubated with $0.25 \%(\mathrm{w} / \mathrm{v})$ trypsin at $37^{\circ} \mathrm{C}$ for $10 \mathrm{~min}$ and then cut into slices and incubated with $0.1 \%$ collagenase at $37^{\circ} \mathrm{C}$ for $40 \mathrm{~min}$. The isolated primary OBs were cultured with DMEM supplemented with $10 \%$ FBS (P303302, PAN-Biotech, Germany), $2 \mathrm{mM}$ L-glutamine, $100 \mathrm{U} / \mathrm{ml}$ penicillin and $100 \mu \mathrm{g} / \mathrm{ml}$ streptomycin at 37 ${ }^{\circ} \mathrm{C}$ in a humidified atmosphere of 5\% CO2 for 10-12 d. The phenotype was determined using an alkaline phosphatase (ALP) staining kit according to the manufacturer's protocol (Beyotime, China) [21]. Salidroside was diluted in cell culture medium to final concentrations of $0.5,1$ and $2 \mathrm{mM}$, and cells were cultured in salidroside for $24 \mathrm{~h}$.

\section{TUNEL assays}

Briefly, chondrosarcoma cells were plated on sterile slides at a density of $5 \times 10^{4}$ cells/well in 24-well plates. After $24 \mathrm{~h}$, the cells were treated as indicated concentrations of salidroside at $37{ }^{\circ} \mathrm{C}$ in $5 \% \mathrm{CO}_{2}$. The cells were then washed with TPBS twice, and subsequently fixed with 4\% paraformaldehyde (PFA) for 30 min. Thereafter, the cells were washed three times with TPBS and incubated with $0.25 \%$ Triton X-100 in PBS sequentially. Cells were then incubated with $50 \mu \mathrm{l}$ TdT-mediated dUTP nick-end labeling (TUNEL) reaction mixture (90\% Label Solutions and 10\% Enzyme) for $60 \mathrm{~min}$ at $37{ }^{\circ} \mathrm{C}$ in the dark. After washing with PBS and staining with DAPI, DNA fragmentation was examined using a Zeiss confocal laser scanning microscope (Zeiss, LSM780). Apoptotic cells with characteristic nuclear fragmentation (staining green) were counted in six randomly selected fields.

\section{Apoptosis assay}

An Annexin V-FITC/PI Detection Kit (BD Biosciences, San Diego, CA, USA) was used for the determination of cell apoptosis. OB cells were exposed to indicated concentrations of salidroside for $24 \mathrm{~h}$, then harvested and washed twice with cold PBS, and re-suspended in $\mathrm{f} 1 \mathrm{X}$ binding buffer at a concentration of $1 \mathrm{X} 10^{6}$ cells/ mL. Subsequently, according to the manufacturer's instructions, the cells were stained with Annexin VFITC and PI for $15 \mathrm{~min}$ at $37 \mathrm{C}$. Then, the cells were analysed immediately using a FACS Calibur flow cytometer.

\section{Caspase-3 activity Assay}

The caspase- 3 activity in cell lysates was assessed using the Caspase-3 Colorimetric Assay Kit (C1116, Beyotime, China) based on the ability of caspase-3 to change acetyl-Asp-Glu-Val-Asp p-nitroanilide (AcDEVD-pNA) into a yellow formazan product (p-nitroanilide, pNA). In brief, at the end of the incubation period, $5 \times 10^{6}$ cells were harvested in cell lysis buffer and incubated on ice for $30 \mathrm{~min}$. After centrifugation at 10, $000 \times \mathrm{g}$ for $15 \mathrm{~min}$, the amount of protein in the supernatant was quantified. One hundred fifty micrograms of protein from each sample was placed in a 96-well plate and incubated with Ac-DEVD-pNA for $1 \mathrm{~h}$ at $37^{\circ} \mathrm{C}$ in the dark, and the absorbance at $405 \mathrm{~nm}$ was then measured with an Infinite ${ }^{\mathrm{TM}} \mathrm{M} 200$ Microplate Reader to detect the pNA released due to caspase- 3 activity. 


\section{Cellular Physiology Cell Physiol Biochem 2017;43:1487-1502 \begin{tabular}{l|l|l} 
and Biochemistry Published online: October 16, 2017 & $\begin{array}{l}\text { (c) } 2017 \text { The Author(s). Published by S. Karger AG, Basel } \\
\text { www.karger.com/cpb }\end{array}$
\end{tabular}}

Zeng et al.: Effects of Salidroside on Chondrosarcoma Cancer Cells

\section{RFP-GFP-LC3 assay}

To evaluate the numbers of autophagosomes and autolysosomes and to analyze autophagic flux, cells were infected with lentiviruses carrying expression cassettes that encode tandem fluorescence-tagged LC3B. Briefly, cells were grown on coverslips at $2 \times 10^{5}$ cells/well plated on coverslips and then using a Premo $^{\mathrm{TM}}$ Autophagy Tandem Sensor RFP-GFP-LC3B (HANBIO, China), in which GFP is more sensitive to acidic conditions than RFP. Twenty-four hours after infection, the cells were treated with $2 \mathrm{mM}$ salidroside for $24 \mathrm{~h}$. All samples were examined under a Zeiss confocal laser scanning microscope (LSM 780, Zeiss) equipped with a $63 \mathrm{x}$ oil immersion objective [22].

\section{Immunocytochemistry}

Cells grown on cover slips were treated as indicated, washed twice with PBS, and then fixed with $4 \%$ PFA for $30 \mathrm{~min}$. After a further three TBST washes, the fixed cells were permeabilized with $0.25 \%$ Triton $\mathrm{X}-100$ in PBS for $10 \mathrm{~min}$ at room temperature. The cells were then blocked in blocking buffer (1\% BSA, $5 \%$ heat-inactivated donkey serum in PBS) for $1 \mathrm{~h}$ at room temperature, and subsequently incubated with TFEB primary antibodies overnight at $4{ }^{\circ} \mathrm{C}$. The cells were then rinsed and incubated with appropriate Alexa Fluor 568-conjugated secondary antibodies for $1 \mathrm{~h}$, followed by an additional three $10 \mathrm{~min}$ TBST washes. The cells were then counterstained with DAPI Staining Solution (C1005, Beyotime, China) and mounted on glass slides using Antifade Mounting Medium (P0126, Beyotime, China). The stained samples were examined using a Zeiss confocal laser scanning microscope (LSM780, Zeiss) equipped with a $63 \times$ oil objective.

\section{Luciferase Reporter Assays}

To detect the activation of TFEB, SW1353 cells were transfected with plasmids encoding TFEB responsive firefly luciferase and Renilla luciferase using Lipofectamine 2000. After transfection for $24 \mathrm{~h}$, the cells were washed with phosphate-buffered saline, serum starved in DMEM/F-12 overnight, and then assayed for luciferase activity using the a dual-luciferase reporter assay kit (Promega Corporation, WI, USA) according to the manufacturer's instructions [23].

\section{Nuclear and Cytoplasmic Protein Extraction}

After stimulation, cytoplasmic and nuclear proteins were extracted from SW1353 cells using nuclear and cytoplasmic extraction reagents obtained from ThermoFisher strictly according to the manufacturer's instructions.

\section{Western blot analysis}

SW1353 cells were treated with the indicated concentrations of salidroside. Then the cells were harvested and washed with cold phosphate-buffered saline (PBS). The proteins were extracted with RIPA Cell Lysis Buffer (Beyotime, China), and maintained on ice for at least $30 \mathrm{~min}$. The lysates were centrifuged at $12,000 \mathrm{~g}$ and $4^{\circ} \mathrm{C}$ for $10 \mathrm{~min}$, and the supernatant was subsequently transferred to a fresh tube. After the protein concentration was measured with the bicinchoninic acid (BCA) method, an equal quantity of total protein per lane was separated by sodium dodecyl sulfate-polyacrylamide gel electrophoresis (SDS-PAGE) and transferred to polyvinylidene fluoride (PVDF) membranes. The membranes were blocked with 5\% non-fat dry milk in $0.05 \%$ Tris-buffered saline and

Table 1. Sequences of primers used in quantitative RT-PCR

Tween 20 (TBST) for $1 \mathrm{~h}$ at room temperature, and incubated overnight at $4^{\circ} \mathrm{C}$ with specialized antibodies. The primary anti-

\begin{tabular}{lcc}
\hline Target gene & Primer & Nucleotide sequence \\
\hline \multirow{2}{*}{ MAP1LC3B } & $\mathrm{F}$ & 5'-AGCAGCATCCAACCAAAATC-3' \\
& $\mathrm{R}$ & 5'-CTGTGTCCGTTCACCAACAG-3' \\
ATP6V0D1 & $\mathrm{F}$ & 5'-TTCCCGGAGCTTTACTTTAACG-3' \\
& $\mathrm{R}$ & 5'-CAAGTCCTCTAGCGTCTCGC-3' \\
UVRAG & $\mathrm{F}$ & 5'-GGCGTCTTCGACATCTTCGG-3' \\
& $\mathrm{R}$ & 5'-GACGGTCTGGCATAATTCCAAA-3' \\
CTSB & $\mathrm{F}$ & 5'-GAGCTGGTCAACTATGTCAACA-3' \\
& $\mathrm{R}$ & 5'-GCTCATGTCCACGTTGTAGAAGT-3' \\
LAMP-1 & $\mathrm{F}$ & 5'-TCTCAGTGAACTACGACACCA-3' \\
& $\mathrm{R}$ & 5'-AGTGTATGTCCTCTTCCAAAAGC-3' \\
TFEB & $\mathrm{F}$ & 5'-ACCTGTCCGAGACCTATGGG-3' \\
& $\mathrm{R}$ & 5'-CGTCCAGACGCATAATGTTGTC-3' \\
ACTB & $\mathrm{F}$ & 5'-CATGTACGTTGCTATCCAGGC-3' \\
& $\mathrm{R}$ & 5'-CTCCTTAATGTCACGCACGAT-3' \\
\hline
\end{tabular}




\section{Cellular Physiology Cell Physiol Biochem 2017;43:1487-1502 \begin{tabular}{l|l|l} 
and Biochemistry Published onlIne: October 16, 2017 & $\begin{array}{l}\text { (c) } 2017 \text { The Author(s). Published by S. Karger AG, Basel } \\
\text { www.karger.com/cpb }\end{array}$ \\
\hline
\end{tabular} \\ Zeng et al.: Effects of Salidroside on Chondrosarcoma Cancer Cells}

bodies used are listed in Table 1. After overnight incubation, the membranes were washed three times and then incubated for 1 $\mathrm{h}$ at room temperature with peroxidase-conjugated secondary antibodies. The blots were then developed using the West Pico enhanced chemiluminescence detection kit (Thermo, USA).

\section{$R T-P C R$}

Total RNA was extracted using TRIzol reagent, and cDNA was synthesized using SuperScript II Reverse Transcriptase

Table 2. Antibodies used for the western blot experiments

\begin{tabular}{lccc}
\hline Antigen & Dilution & Catalogue number & Supplier \\
\hline LC3 & $1: 1000$ & L7543 & Sigma \\
ACTIN & $1: 5000$ & A5441 & Sigma \\
TFEB & $1: 1000$ & PA1-31552 & Thermo fisher \\
BCL2 & $1: 1000$ & ab692 & Abcam \\
BAX & $1: 1000$ & ab32503 & Abcam \\
CL-PAPR & $1: 1000$ & 5625 or 9848 & Cell Signaling Technology \\
P62/SQSTM1 & $1: 1000$ & ab91526 & Abcam \\
H3 & $1: 1000$ & SAB4500352 & Sigma \\
p-TFEB(Ser142) & $1: 200$ & ABE1971 & Merck Millipore \\
P-70S6K & $1: 1000$ & 9204 & Cell Signaling Technology \\
70S6K & $1: 1000$ & 2708 & Cell Signaling Technology \\
p-4EBP1 & $1: 1000$ & 9456 & Cell Signaling Technology \\
4EBP1 & $1: 1000$ & ab2606 & Abcam \\
anti-mouse & $1: 1000$ & A0208 & Beyotime Company \\
(secondary antibody) & & & \\
anti-rabbit & $1: 1000$ & A0216 & Beyotime Company \\
(secondary antibody) & & & \\
anti-goat & $1: 1000$ & A0181 & Beyotime Company \\
(secondary antibody) & & &
\end{tabular}
(Invitrogen, USA). qRT-PCR and data collection were performed with an iQ5 Real-Time PCR Detection System (Bio-Rad, USA) system. The primers used to amplify the indicated genes are listed in Table 2 . The mean fold change is shown as the natural logarithm of RQ values, and the error was estimated by evaluating the $2^{-\triangle \triangle \mathrm{Ct}}$ equation using $\triangle \triangle \mathrm{Ct}$ plus the standard deviation and $\triangle \triangle \mathrm{Ct}$ minus the standard deviation.

\section{Measurement of Reactive Oxygen Species (ROS)}

Cultured Cells were treated with salidroside in the presence or absence of NAC for $2 \mathrm{~h}$ and then loaded with $25 \mathrm{mM}$ DCFH-DA. After incubation for $30 \mathrm{~min}$ at $37^{\circ} \mathrm{C}$ in a $5 \% \mathrm{CO}_{2}$ incubator, the cells were washed twice with HBSS solution, and examined with an Infinite ${ }^{\mathrm{TM}}$ M200 Microplate Reader to detect the intracellular accumulation of ROS.

\section{Gene knockdown using siRNA}

The siRNAs to Beclin1, TFEB or control siRNA were all purchased from Shanghai GenePharma. Cells were transfected with siRNA using Lipofectamine 2000 (Invitrogen, USA) according to the manufacturer's instructions. Cells were incubated for $48 \mathrm{~h}$ before further treatment.

\section{Statistical analysis}

The significance of differences between groups was assessed using a one-way ANOVA, followed by Tukey's post-hoc test. $\mathrm{P}<0.05$ indicated statistical significance; all tests were two-sided and no corrections were applied for multiple significance testing. All experiments were repeated at least three times. Drug and biomarker distributions are represented as the mean values \pm s.e.m.

\section{Results}

\section{Salidroside induces apoptosis in SW1353 cells}

TUNEL staining was applied to detect the effects of salidroside treatment on apoptosis in SW1353 cells. Cultured SW1353 cells were treated with increasing concentrations of salidroside. As shown in Fig. 1A, cells were treated with $0.5,1$ and $2 \mathrm{mM}$ salidroside for 24 $\mathrm{h}$, which increased the proportion of apoptotic cells to $5.1 \%, 24.7 \%$, and $37.8 \%$ of total cells, respectively, compared to $2.8 \%$ in the control. As key executors of cell apoptosis, both cleaved PARP and the ratio of Bax to Bcl-2 proteins increased in SW1353 cells treated with different concentration of salidroside for $24 \mathrm{~h}$ (Fig. 1B). We also found that treatment with salidroside increased caspase-3 activity in a dose-dependent manner (Fig. 1C). Taken together, these results demonstrate that apoptosis was involved in the response of SW1353 cells to salidroside treatment. 
Fig. 1. Salidroside induces apoptosis in SW1353 cells. (A) SW1353 cells were treated with $0.5 \mathrm{mM}$, $1 \mathrm{mM}$, or $2 \mathrm{mM}$ salidroside for $24 \mathrm{~h}$ and stained with TUNEL. (B) SW1353 cells were treated with different concentrations of salidroside for $24 \mathrm{~h}$, and the expression levels of cleaved-PARP (ClPARP), Bcl-2 and Bax were then assessed by western blotting; (C) Caspase-3 activity of SW1353 cells after 24 $\mathrm{h}$ of salidroside treatment at the indicated concentrations. The percentages of Caspase-3 activity are presented in bar charts; the data are presented as the mean \pm SEM. ${ }^{*} \mathrm{P}<0.05,{ }^{*} \mathrm{P}<0.01$ versus the control group $(n=6)$.

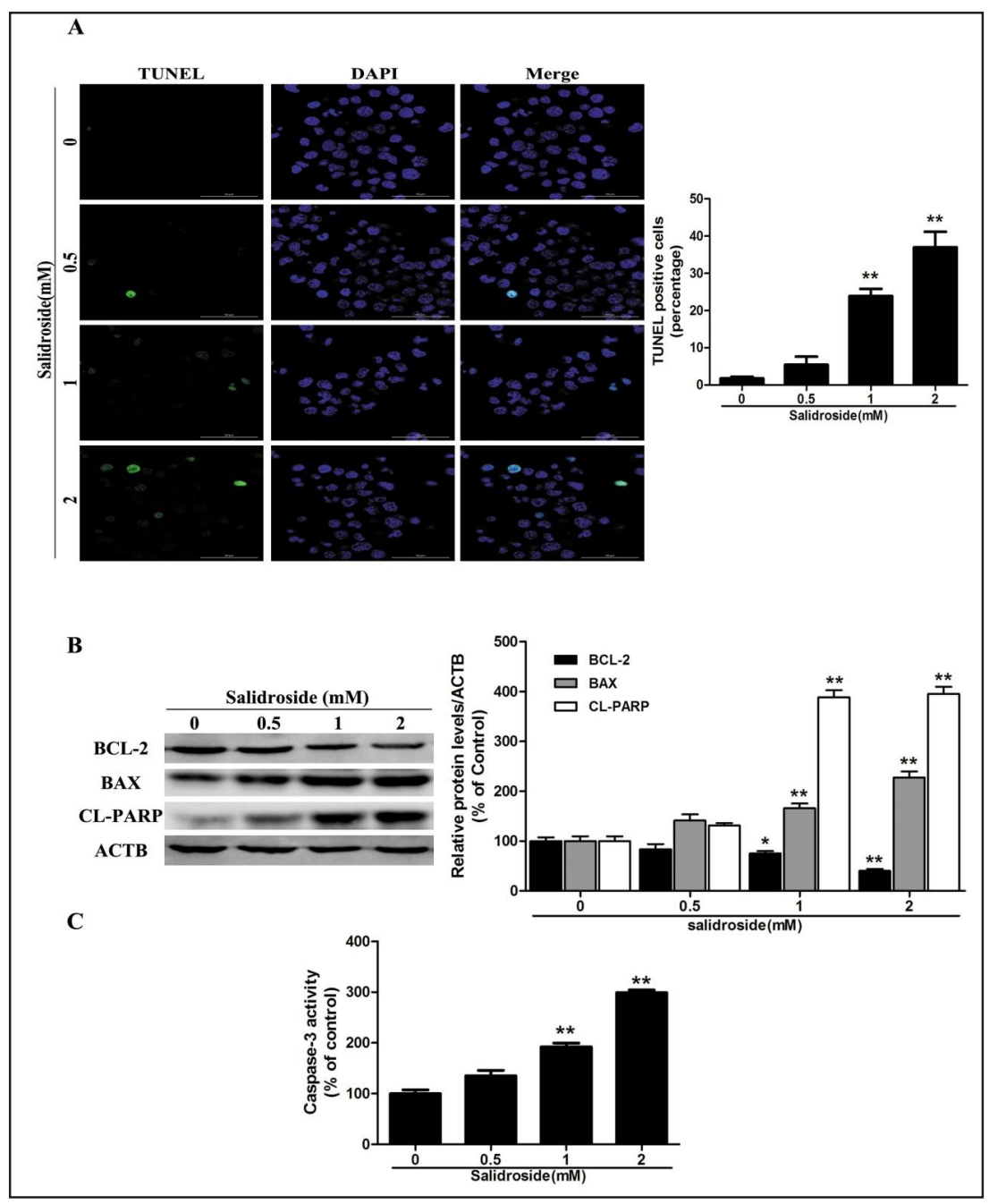

Salidroside induces autophagy in SW1353 cells

Several studies have suggested that autophagy may act as a protective mechanism in tumor cells and that autophagy induction is a common event in cancer cells in response to various chemotherapeutic treatments $[24,25]$. Thus, we used the membrane-bound, autophagosome-associated form of microtubule- associated protein 1 light chain 3 (LC3II), as a marker to monitor the effect of salidroside on autophagy induction [11]. First, the conversion of the cytoplasmic form of LC3 (LC3-I, $18 \mathrm{kDa}$ ) to the pre-autophagosomal and autophagosomal membrane-bound form of LC3 (LC3-II, $16 \mathrm{kDa}$ ) was biochemically demonstrated by western blotting in a dose-dependent manner(Fig. 2A). We next examined the change in the SQSTM1 protein levels. This protein is selectively incorporated into autophagosomes via direct binding to LC3 and is efficiently degraded by autophagy [26]. We observed an evident dose-dependent decrease in the SQSTM1 protein levels in SW1353 cells that were treated with salidroside, confirming that autophagic flux was intact in the salidroside-treated cell (Fig. 2A). Moreover, we transfected SW1353 cells with tandem fluorescent mRFP-GFP-LC3B (tf-LC3), a novel marker that allows for the assessment of autophagic flux, that is, the complete processing of autophagosomes after fusing with lysosomes, using fluorescence microscopy. Salidroside increased the number of red puncta in the merged image, which indicates the formation of autolysosomes(Fig. 2B). Taken together, our results indicate that salidroside treatment induced autophagic flux in human chondrosarcoma cells. 
Fig. 2. Salidroside induces autophagy in SW1353 cells. (A) SW1353 cells were treated with different concentrations of salidroside for $24 \mathrm{~h}$, and the expression levels of the autophagy-associated proteins LC3-I/II, and p62 were then assessed by western blotting. (B) The co-localization of GFP-LC3 puncta and RFP-LC3 puncta was examined by confocal microscopy in SW1353 cells infected using a Premo ${ }^{\mathrm{TM}}$ Autophagy Tandem Sensor RFP-GFP-LC3B Kit that were treated with $2 \mathrm{mM}$ salidroside for $24 \mathrm{~h}$; the data are presented as the means \pm SEM. ${ }^{*} \mathrm{P}<0.05,{ }^{* *} \mathrm{P}<0.01$ versus the control group $(n=6)$.

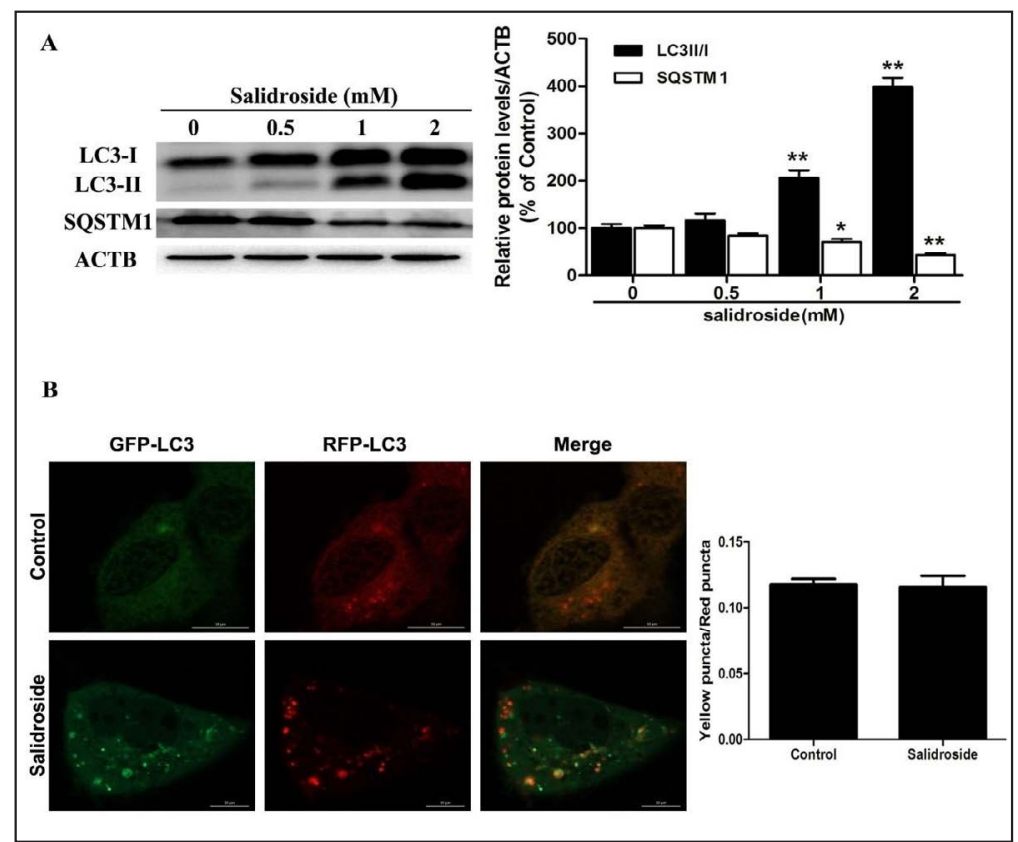

A
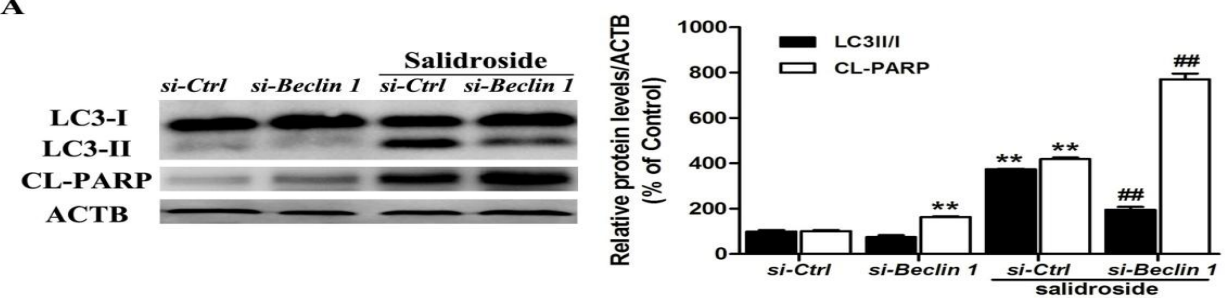

B
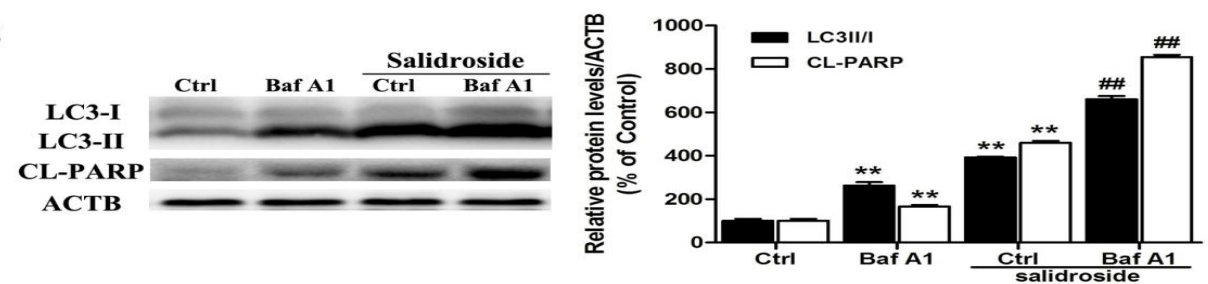

$r$

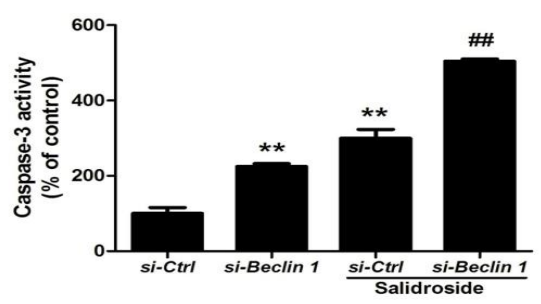

D

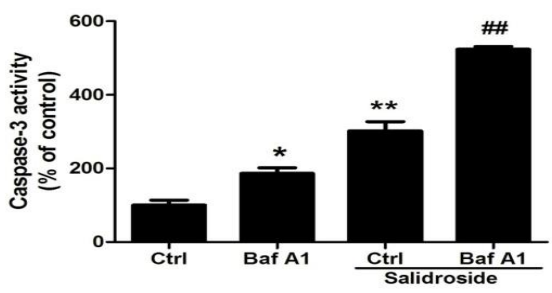

Fig. 3. Autophagy alleviates salidroside-induced apoptosis in SW1353 cells. SW1353 cells were treated with siRNA against Beclin1 and incubated with $2 \mathrm{mM}$ salidroside for another $24 \mathrm{~h}$. (A)The LC3 and Cl-PARP levels and $(\mathrm{C})$ the caspase 3 activity were measured. The values are presented as the means $\pm \mathrm{SEM} . * * \mathrm{P}<0.01$ versus the si-control group, ${ }^{\# \# P}<0.01$ versus the si-control+ salidroside group. SW1353 cells were pretreated with $10 \mathrm{nM}$ Bafilomycin A1 for 2 hand incubated with $2 \mathrm{mM}$ salidroside for another $24 \mathrm{~h}$. (B)The LC3 and Cl-PARP level and (D) the caspase 3 activity were measured; the values are presented as the means $\pm \mathrm{SEM}$. ${ }^{*} \mathrm{P}<0.05$, ${ }^{* *} \mathrm{P}<0.01$ versus the control group, ${ }^{\# \#} \mathrm{P}<0.01$ versus the salidroside group $(\mathrm{n}=6)$. 
Fig. 4. Salidroside increases TFEB activity in SW1353 cells. (A) SW1353 cells were treated with different concentrations of salidroside for $24 \mathrm{~h}$, and the mRNA level of TFEB was then analyzed by RTPCR; (B) SW1353 cells were treated with different concentrations of salidroside for $24 \mathrm{~h}$, and the levels of cytoplasmic and nuclear TFEB were then analyzed by western blotting, as shown in left panel; GAPDH and Histone $\mathrm{H} 3$ were the internal standards for protein loading, respectively. (C) Immunofluorescence of SW1353 cells incubated with anti-TFEB antibody and DAPI after salidroside (2 mM) treatment for 24 h;(D)SW1353 cells were transfected with TFEBluciferase expression

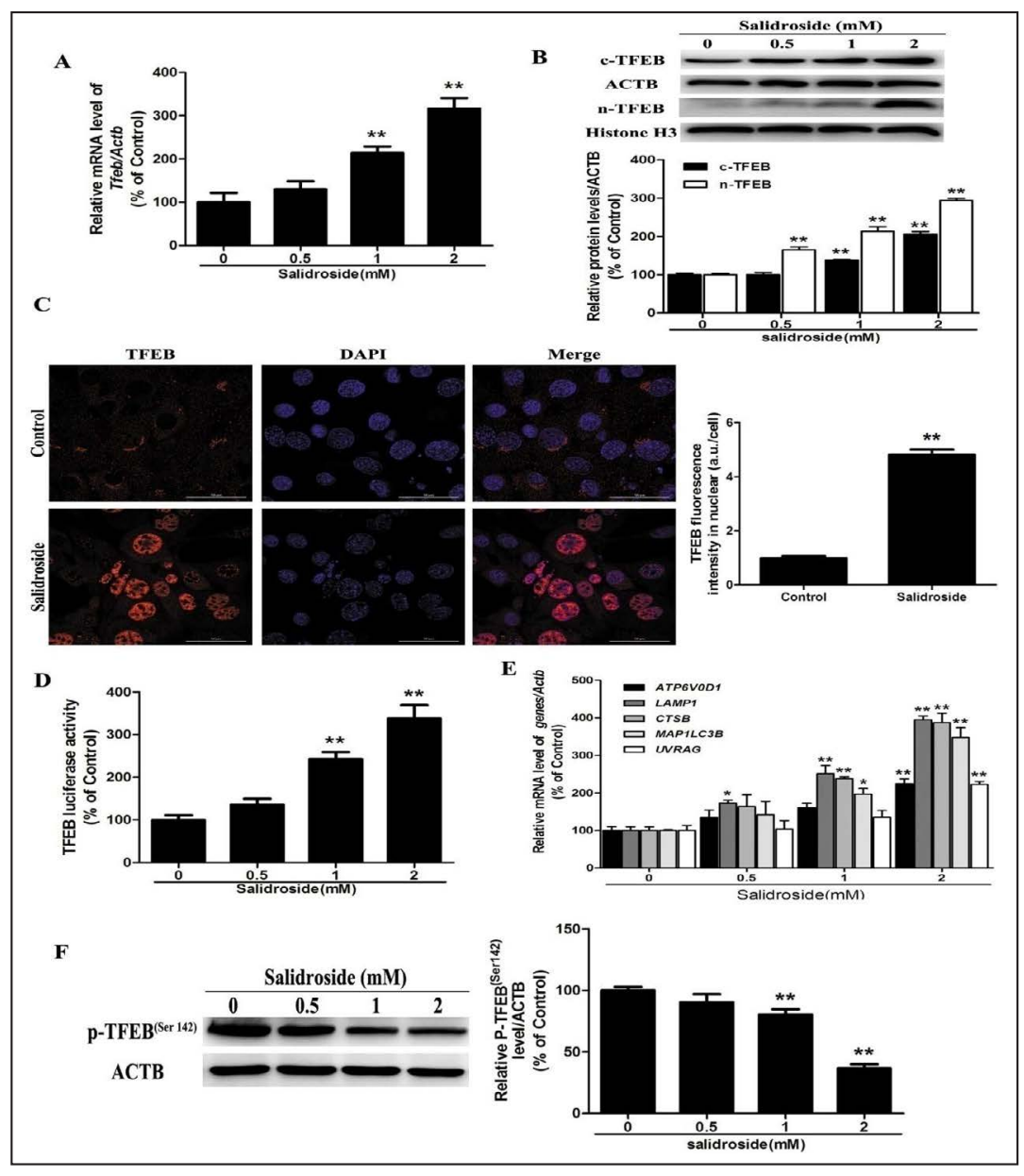
vector and incubated with different concentrations of salidroside. The luciferase activity was then measured.(E) The level of TFEB $^{(\text {Ser142) }}$ protein was analyzed by western blotting; GAPDH was the internal standard for protein loading. (F)The mRNA levels of TFEB target genes were measured using RT-PCR. The values are presented as the means $\pm S E M .{ }^{*} \mathrm{P}<0.05,{ }^{* *} \mathrm{P}<0.01$ versus the control group $(\mathrm{n}=6)$.

Inhibition of salidroside-induced autophagy sensitizes SW1353 cells to salidroside-induced apoptotic cell death

Increasing evidence indicates that autophagy can prolong the survival of cancer cells and enhance their resistance to apoptosis $[27,28]$. Because the manipulation of autophagy may improve the efficacy of anticancer therapeutics, we were eager to assess the effect of salidroside-elicited autophagy on the survival of SW1353 cells. Beclin1 is an essential protein for autophagy activation, and beclin 1 deficiency can significantly interrupt autophagy [29]. Therefore, autophagy was inhibited in SW1353 cells by transfecting them with Beclin1siRNA to determine the precise role of autophagy in salidroside-exposed SW1353 cells. SW1353 cells transfected with Beclin-1 siRNA showed a reduced LC3-II accumulation after salidroside treatment compared with a scrambled siRNA-transfected control cells, indicating the involvement of Beclin-1 in salidroside-mediated autophagy in SW1353 cells(Fig. 3A). To test the potential cytoprotective role of autophagy in our system, we inhibited autophagy in SW1353 cells using bafilomycin A1 (Baf A1), which is an inhibitor of lysosomal V-ATPase and results in the accumulation of autophagosomes due to a defect in the fusion between autophagosomes and lysosomes [26]. We observed that the presence of $10 \mathrm{nM}$ Baf A1 significantly increased the level of LC3II and cleaved PARP in SW1353 cells treated with $2 \mathrm{mM}$ salidroside (Fig. 3B). In agreement with the data derived from pharmacological inhibitors, the knockdown of Beclin-1 by siRNA enhanced the level of cleaved PARP, as assessed using KARGER 
$\mathbf{A}$
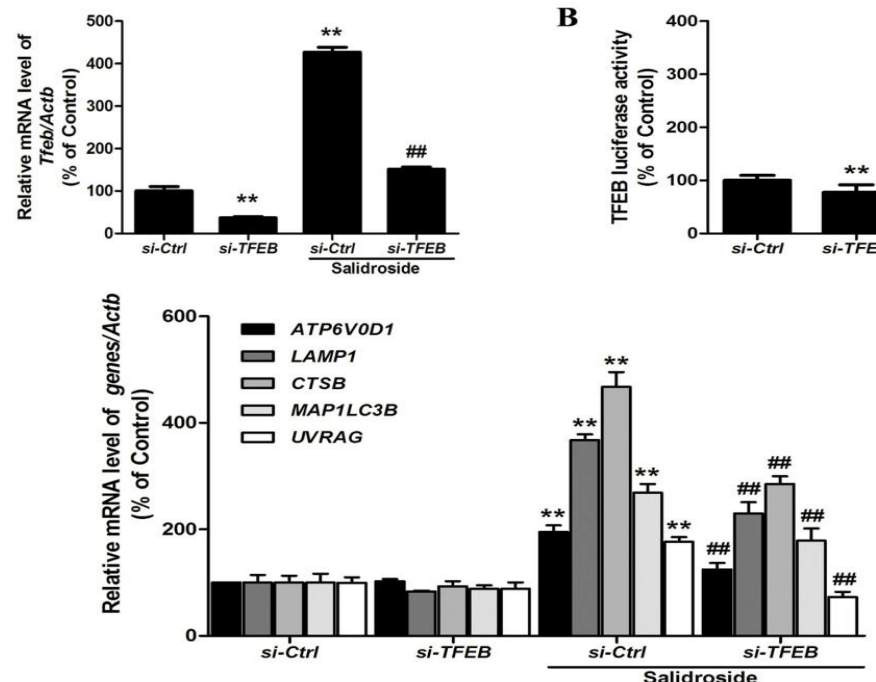

D

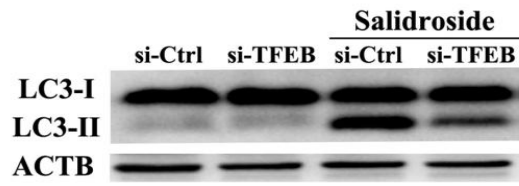

C
B

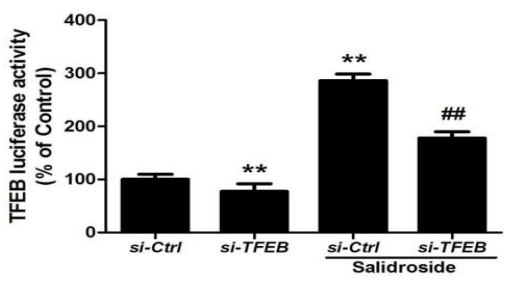

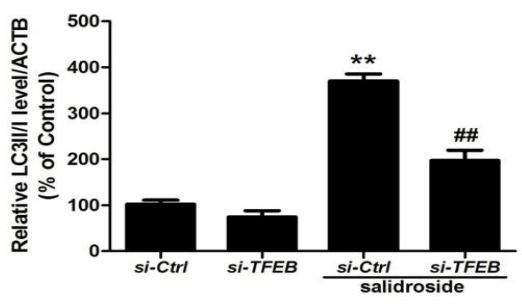

Fig. 5. TFEB mediates salidroside-induced autophagy. (A) The mRNA levels of autophagy-related genes were determined in TFEB siRNA-transfected SW1353 cells using RT-PCR. (B)SW1353 cells were treated with siRNA against TFEB or control siRNA and then incubated with $2 \mathrm{mM}$ salidroside for another $24 \mathrm{~h}$ before measuring the Luciferase activity. (C)The mRNA levels of TFEB target genes were measured using RT-PCR. (D) The levels of LC3II/LC3I were measured using western blotting. The values are presented as the means \pm SEM. ${ }^{* *} \mathrm{P}<0.01$ versus the control group, ${ }^{\# \#} \mathrm{P}<0.01$ versus the si-Ctrl+ salidroside $(2 \mathrm{mM})$ group $(\mathrm{n}=6)$.

western blotting analysis (Fig. 3C). Moreover, salidroside markedly increased the caspase-3 activity when autophagy flux was inhibited (Fig. 3D and 3E). These results show that inhibiting of salidroside-induced autophagy sensitized SW1353 cells to salidroside-induced apoptotic cell death.

\section{Salidroside induces TFEB nuclear translocation in SW1353 cells}

Transcription factor EB (TFEB), which is a member of the MiT/TFE family, is a major regulator of lysosomal biogenesis [30]. Many target genes of TFEB participate in substrate degradation and lysosome-associated processes, such as autophagy and endocytosis [31], and recent studies have suggested a correlation between autophagy and the TFEB pathway in human cancer [19]. Based on these results, we investigated the involvement of TFEB in the effect of salidroside on SW1353 cells. As shown in Fig. 4A, TFEB mRNA expression increased significantly after exposure to different concentrations of salidroside for $24 \mathrm{~h}$. The activation of TFEB was measured based on the detection of its translocation into cell nuclei from its initial location in the cytoplasm where it exists in an inactive form [32]. Western blotting for TFEB protein in the nuclear and cytosolic fractions of SW1353 cells indicated that salidroside treatment increased the level of nuclear TFEB (Fig. 4B), and immunofluorescence staining produced similar results (Fig. 4C). Moreover, the entry of TFEB into the nucleus was accompanied by an upregulation of "TFEB-responsive genes"[33]. As expected, salidroside significantly increased the TFEB luciferase activity and the mRNA abundance of 5 tested genes, including ATP6V0D1, LAMP1, CTSB, MAP1LC3B and UVRAG(Fig. 4D and 4E). To 
Fig. 6. ROS is an upstream signaling molecule that activates the TFEB-dependent autophagy pathway. (A) SW1353 cells were treated with salidroside $(0.5$, 1 or $2 \mathrm{mM}$ ) for $24 \mathrm{~h}$ and then examined for the intracellular accumulation of ROS using DCFH-DA; ROS levels were measured using anInfinite ${ }^{\mathrm{TM}}$ M200 Microplate reader; SW1353 cells were exposed to NAC ( $5 \mathrm{mM})$ for $2 \mathrm{~h}$, followed by treatment with salidroside(2 $\mathrm{mM}$ ) for $24 \mathrm{~h}$. (B) The ROS levels were measured with an Infinite ${ }^{\mathrm{TM}}$ M200 Microplate reader; (C) The expression levels of nuclear and cytoplasmic TFEB were measured. (D) The mRNA level of TFEB was detected by RT-PCR. (E) The TFEB Luciferase activity was then measured. (F)The mRNA levels of TFEB target genes were measured using RT-PCR. The values are presented as the means \pm SEM. ${ }^{* *} \mathrm{P}<0.01$, versus the control group; ${ }^{\#} \mathrm{P}<0.05$, \#\# $\mathrm{P}<0.01$ versus the salidroside (2 $\mathrm{mM})$ group. $(n=6)$

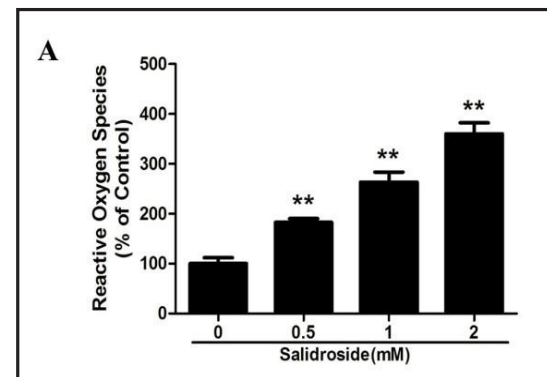

B
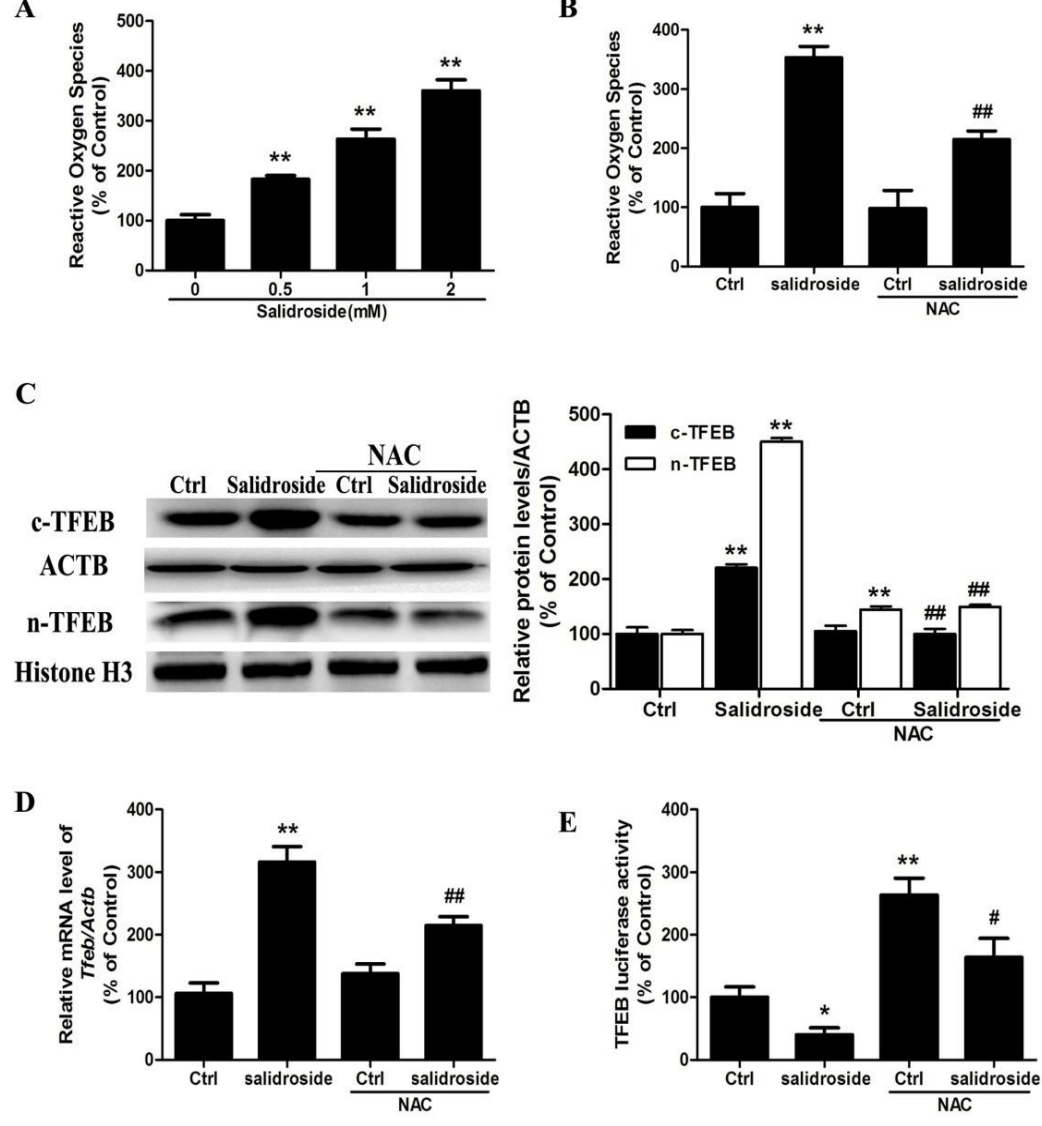

$\mathbf{E}$

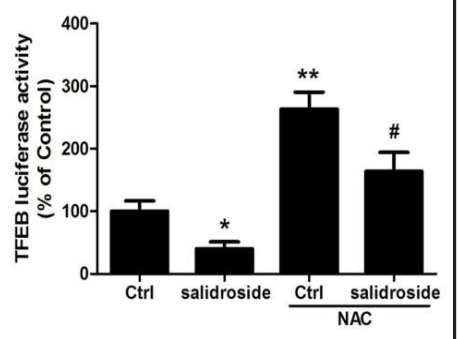

F

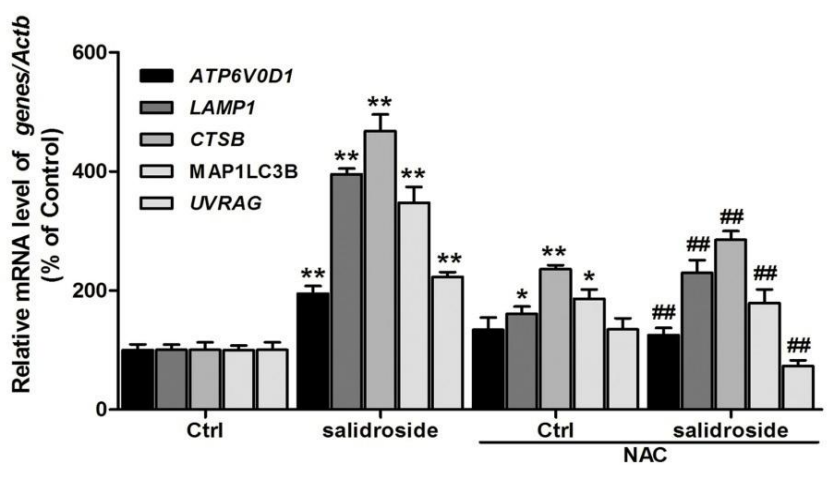

investigate the mechanism underlying salidroside-elicited TFEB nuclear translocation, we assessed the phosphorylation status of TFEB. Because Ser142 dephosphorylation is the primary, and sufficient event leading to TFEB nuclear translocation, we assessed the level of TFEB phosphorylation at Ser142. Salidroside treatment significantly decreased TFEB phosphorylation at Ser142 (Fig. 4F). Collectively, these data show that salidroside induced TFEB $^{(\text {Ser142) }}$ dephosphorylation, subsequently activated TFEB nuclear translocation, and increased TFEB reporter activity, which contributed to the expression of autophagy-related genes and lysosomal biogenesis.

\section{TFEB mediates salidroside-induced autophagy in SW1353 cells}

To further assess the ability of TFEB to salidroside-induced autophagy, TFEB was inhibited with TFEB-specific siRNA prior to salidroside in SW1353 cells. As shown in Fig. 5A and 5B, TFEB-siRNA abrogated salidroside-induced the TFEB expression and luciferase 
Fig. 7. NAC increased salidros i d e - in d u c e d apoptosis after the inhibition of autophagy. SW1353 cells were treated with salidroside (2 mM) for $24 \mathrm{~h}$ after pre-incubation with or without NAC (5 mM) for 2 h. (A) The levels of LC3II/LC3I were measured using western blotting. (B) The caspase-3 activity was measured. (C) apoptotic cells stained with TUNEL. The values are presented as the means \pm SEM. ${ }^{* *} \mathrm{P}<0.01$, versus the control group; \#\# $\mathrm{P}<0.01$ versus the salidroside (2 mM) group $(n=6)$.

A
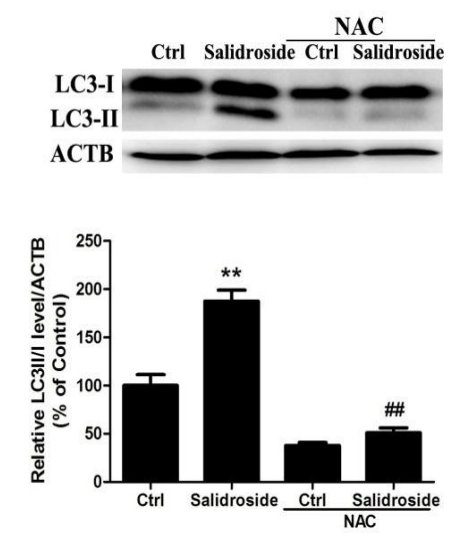

C
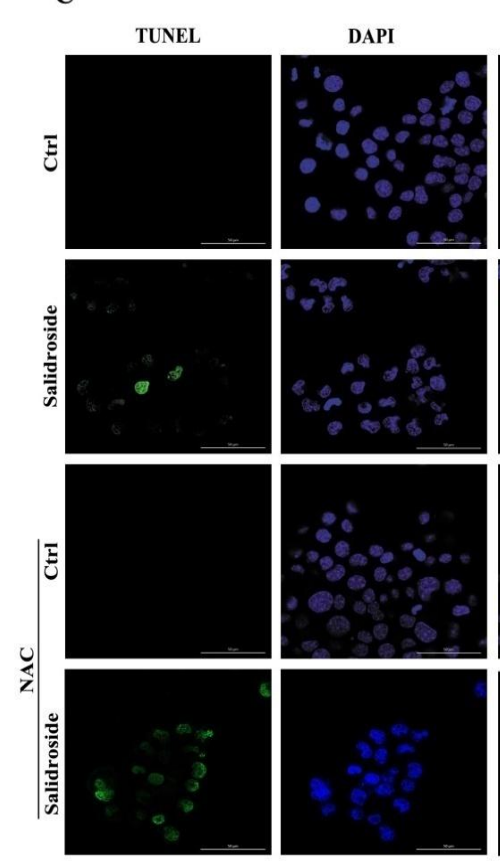

B

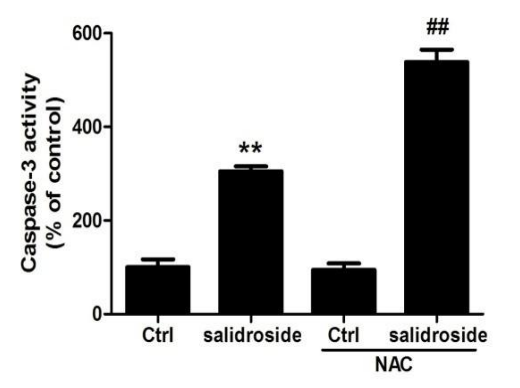

activity. Notably, the inhibition of TFEB activity decreased salidroside-induced lysosomal biogenesis and autophagy-related genes expression (Fig. 5C). Additionally, the protein levels of LC3 II/LC3 I were also suppressed (Fig. 5D). These results suggested that salidroside induced autophagy by activating TFEB pathway in SW1353 cells.

ROS is an upstream signaling molecule that activates the TFEB-dependent autophagy pathway

Accumulating evidence indicates that intracellular ROS can induce apoptosis and autophagy in cancer cells [34-37]. Thus, we examined the role of ROS generation in salidroside induced apoptosis and autophagy in SW1353 cells. Salidroside significantly induced ROS generation in a dose-dependent manner (Fig. 6A) and the ROS scavenger N-acetyl-Lcysteine (NAC) significantly decreased intracellular ROS generation (Fig. 6B). In addition, pretreatment with NAC significantly inhibited the activation of TFEB in salidroside-treated cells, indicating that ROS is an upstream signaling molecule that activates the TFEB pathway (Fig. 6D-E). NAC also significantly suppressed the protein expression of LC3-II, suggesting

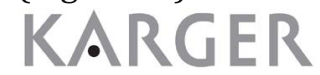




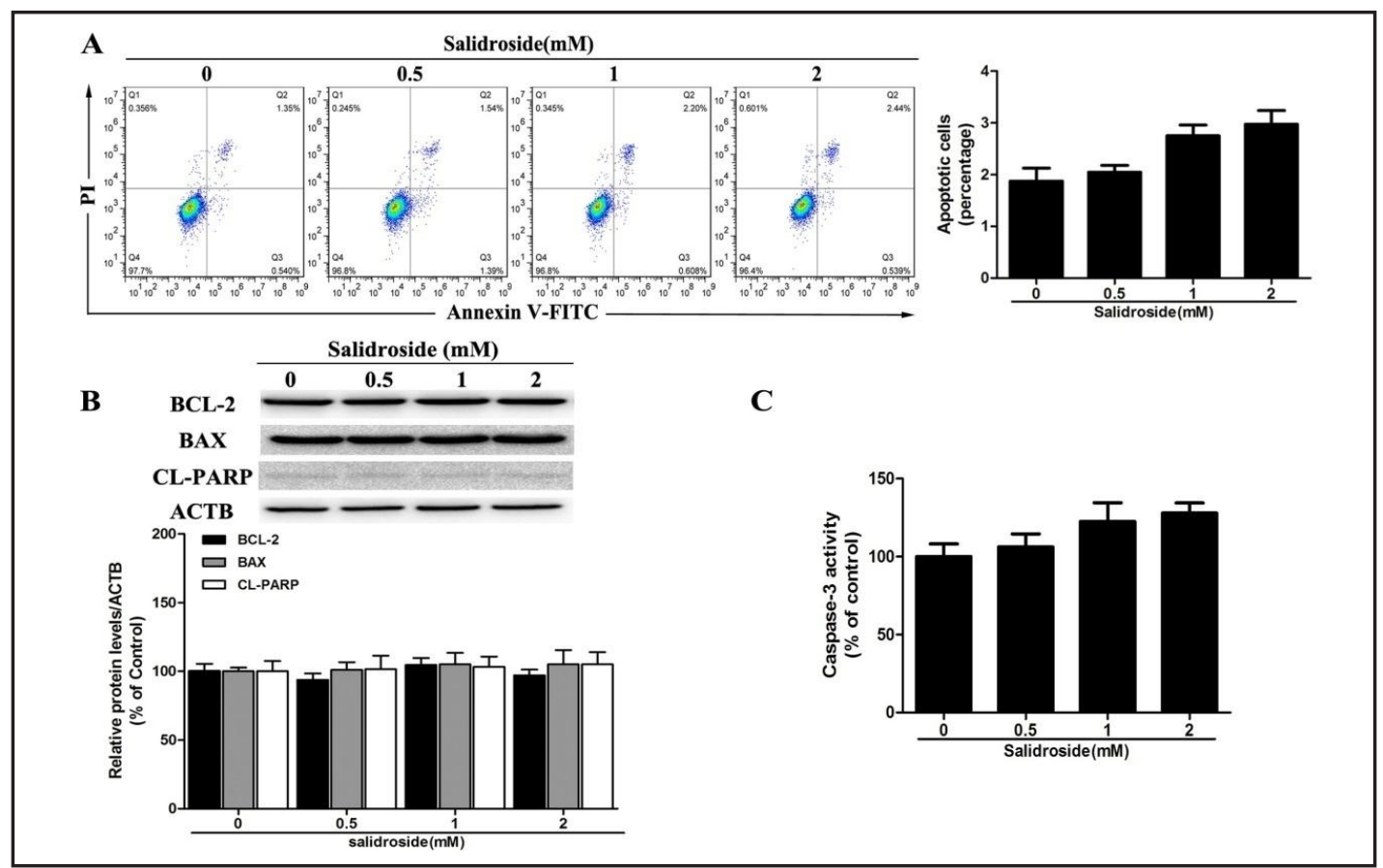

Fig. 8. Salidroside does not induce apoptosis in OBs. (A) OBs were treated with $0.5 \mathrm{mM}, 1 \mathrm{mM}$, and $2 \mathrm{mM}$ of salidroside for $24 \mathrm{~h}$ and stained with Annexin V/PI, then analyzed by flow cytometry. The percentages of Annexin V-positive cells were presented in bar charts; (B) OBs were treated with different concentration of salidroside for $24 \mathrm{~h}$ then western blot analysis was performed to assess the expression level of CleavedPARP (CL-PARP), BCL-2 and BAX. (B) caspase-3 activity of OBs after $24 \mathrm{~h}$ of salidroside treatment at the indicated concentrations. The percentages of caspase- 3 activity were presented in bar charts; $(n=3)$

that autophagy was inhibited by NAC administration (Fig. 7A). Moreover, the incubation of cells with NAC for $2 \mathrm{~h}$ prior to treatment with salidroside increased Caspase- 3 activity and the proportion of apoptotic cells (Fig. 7B and 7C). Taken together, these results showed that ROS is involved in salidroside-induced autophagy in SW1353 cells, and salidroside-promoted TFEB signaling partly depends on ROS generation.

\section{Discussion}

Chondrosarcoma is a common malignant histological tumor; worldwide, the incidence of chondrosarcoma is second only to that of primary tumors of bone, and male-to-female ratio of the incidence of this disease is 1.5:1[38]. Recently, the combination of curative surgery with chemotherapy has improved the five-year of patients with chondrosarcoma, but many of these patients either do not respond to chemotherapy or develop drug resistance to current chemotherapy regimens [39]. Therefore, the discovery of effective anticancer activities with few side effect chemotherapeutic agents is necessary and urgent.

Salidroside is a phenylpropanoid glycoside isolated from a popular traditional Chinese medicinal plant, Rhodiola rosea L, and has been proven to inhibit cell proliferation, arrest the cell cycle, and promote the apoptosis of human cancer cells [40]. Salidroside also plays an antitumor role by inhibiting tumor metastasis and reducing angiogenesis [10]. In our study, cleaved PARP, the ratio of Bax to Bcl-2 protein and caspase-3 activity increased in SW1353 cells after treatment with salidroside, which indicated that salidroside is a potential treatment for chondrosarcoma. Importantly, apoptosis was not detected in primary rat osteoblasts (OBs) after salidroside treatment, which confirmed the selective cytotoxic action of salidroside against human chondrosarcoma cells (Fig. 8). 


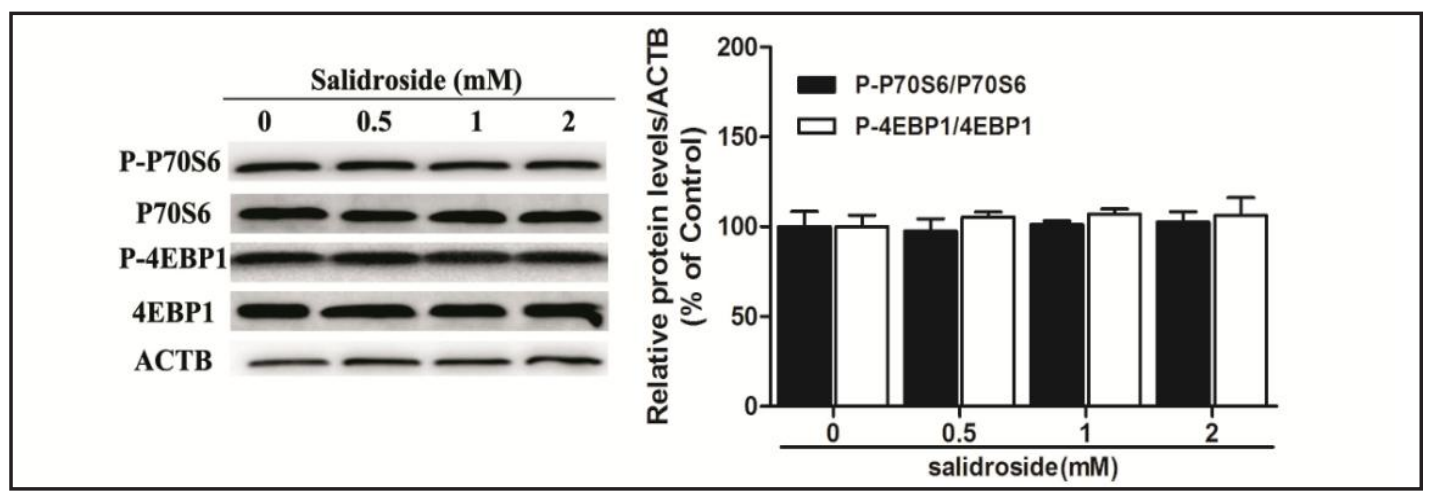

Fig. 9. Salidroside has no effect on mTORC1 pathway in SW1353 cells. SW1353 cells were treated with different concentration of salidroside for $24 \mathrm{~h}$ then western blot analysis was performed to assess the expression level of p-p70S6K and p-4EBP1. $(n=4)$

Autophagy is a lysosome dependent mechanism by which dysfunctional or damaged intracellular organelles are broken down and recycled through the lysosomes. As a putative adaptive catabolic process, autophagy plays an important role in many human cancers, and the inhibition of autophagy in these conditions can lead to increased chondrosarcoma cell death. Reumann et al. reported that the inhibition of autophagy increased 2-Methoxyestradiolinduced cytotoxicity in SW1353 chondrosarcoma cells [41], and Xing et al. found that the knockdown of HOTAIR inhibited autophagy, which favored chondrosarcoma cell death [42]. Moreover, Gao et al. observed that autophagy protected chondrosarcoma cells from siBMPR2-induced apoptotic cell death [43]. Consistent with these findings, our experiments showed that the pharmacological or genetic inhibition of autophagy leads to increased salidroside-induced apoptosis, indicating that salidroside-mediated autophagy is a prosurvival mechanism rather than a pro-death mechanism. We also examined the potential mechanisms underlying salidroside-induced autophagy. TFEB has been shown to regulate autophagy in various human cancers and has been well demonstrated to play key roles in several biological activities, including autophagy, apoptosis, inflammation, survival and metabolic disorders [44]. The activation of TFEB was measured based on the detection of its translocation into cell nuclei from its initial location in the cytoplasm where it exists in an inactive form. The nuclear translocation of TFEB stimulates autophagy in various cell types by inducing lysosomal biogenesis and increasing the expression of numerous autophagy-related genes [45]. In our research, salidroside treatment activated TFEB nuclear translocation and increased TFEB reporter activity, which contributed to lysosomal biogenesis and the expression of autophagy-related genes, including genes encoding several subunits of v-ATPase (ATP6V0D1), lysosomal transmembrane proteins (LAMP1), lysosomal hydrolases (CTSB), and proteins that play an essential role in the formation of autophagosomes (MAP1LC3B) as well as their degradation (UVRAG) [46]. Moreover, the siRNA-mediated down-regulation of TFEB suppressed salidroside-induced autophagy indicating that the TFEB signaling pathway is involved in salidroside-induced autophagy in the human chondrosarcoma cells.

However, the mechanism that underlies the salidroside-mediated enhancement of TFEB activity and nuclear translocation remains elusive. Recent evidence has suggested that mTORC1 regulates the intracellular localization of TFEB. In certain circumstances, TFEB is recruited to the lysosomal surface, where it undergoes mTORC1-dependent phosphorylation. Specifically, mTORC1 phosphorylates TFEB at several residues, but Ser142 is particularly relevant because the phosphorylation of this residue creates a binding site for the cytosolic chaperone 14-3-3. Interaction with 14-3-3 results in sequestration of the TFEB in the cytosol. Conversely, inactivation of the mTORC1, together with dephosphorylation of Ser142, prevents binding to 14-3-3, which results in the rapid accumulation of TFE3 in 


\section{Cellular Physiology Cell Physiol Biochem 2017;43:1487-1502 \begin{tabular}{l|l|l} 
and Biochemistry 10.1159/000481971 & $\begin{array}{l}\text { C } 2017 \text { The Author(s). Published by S. Karger AG, Basel } \\
\text { www.karger.com/cpb }\end{array}$ \\
\hline
\end{tabular}

the nucleus $[45,47]$. However, the phosphorylation of p-70S6K and p-4EBP1, which are mTORC1 substrates, did not significantly change after salidroside treatment, suggesting that mTORC1 signaling is not involved in salidroside-induced TFEB-dependent autophagy (Fig. 9)[48]. Other studies have linked the accumulation of ROS to TFEB activation in the invasion and migration of cancer [49]. We found that salidroside induced ROS generation in a dosedependent manner, an effect that was abolished by pretreating cells with NAC. Furthermore, the incubation of human chondrosarcoma cells with NAC for $2 \mathrm{~h}$ prior to treatment with salidroside revealed that the inhibition of ROS generation abrogated the effect of salidroside on the TFEB pathway. Based on these results, we suggest that ROS are important cellular mediator that triggers the TFEB-dependent pathway after the administration of salidroside in chondrosarcoma cells.

Collectively, we report that salidroside induces marked apoptosis in human chondrosarcoma cells and rapidly activates an autophagic process. Alink between salidrosideinduced autophagy and ROS production was also observed. Moreover, the pharmacological or genetic inhibition of TFEB-dependent autophagy sensitized chondrosarcoma cells to salidroside-induced apoptosis. These findings indicate that autophagy plays a cytoprotective role in chondrosarcoma cells treated with salidroside, and the inhibition of autophagy may improve the therapeutic efficacy of salidroside treatment for chondrosarcoma.

\section{Acknowledgements}

This work was supported by the Medical Scientific Research Project of the Hunan province of China (No. B2016172) and the Natural Science Foundation of Hunan province of China (No. 2017JJ4068).

\section{Disclosure Statement}

The author(s) declare no potential conflicts of interest with respect to the research, authorship, and/or publication of this article.

\section{References}

1 Lin CY, Tzeng HE, Li TM, Chen HT, Lee Y, Yang YC, Wang SW, Yang WH, Tang CH: WISP-3 inhibition of miR-452 promotes VEGF-A expression in chondrosarcoma cells and induces endothelial progenitor cells angiogenesis. Oncotarget 2017;8:39571-39581.

2 Chang L, Shrestha S, LaChaud G, Scott MA, James AW: Review of microRNA in osteosarcoma and chondrosarcoma. Med Oncol 2015;32:613.

-3 Gelderblom H, Hogendoorn PC, Dijkstra SD, van Rijswijk CS, Krol AD, Taminiau AH, Bovee JV: The clinical approach towards chondrosarcoma. Oncologist 2008;13:320-329.

-4 Eo SH, Kim JH, Kim SJ: Induction of G(2)/M Arrest by Berberine via Activation of PI3K/Akt and p38 in Human Chondrosarcoma Cell Line. Oncol Res 2014;22:147-157.

5 Lee HP, Li TM, Tsao JY, Fong YC, Tang CH: Curcumin induces cell apoptosis in human chondrosarcoma through extrinsic death receptor pathway. Int Immunopharmacol 2012;13:163-169.

6 Dai Z, Lei P, Xie J, Hu Y: Antitumor effect of resveratrol on chondrosarcoma cells via phosphoinositide 3-kinase/AKT and p38 mitogen-activated protein kinase pathways. Mol Med Rep 2015;12:3151-3155.

7 Recio MC, Giner RM, Manez S: Immunmodulatory and Antiproliferative Properties of Rhodiola Species. Planta Med 2016;82:952-960.

8 Kucinskaite A, Briedis V, Savickas A: [Experimental analysis of therapeutic properties of Rhodiola rosea L. and its possible application in medicine]. Medicina (Kaunas) 2004;40:614-619.

-9 Fan XJ, Wang Y, Wang L, Zhu M: Salidroside induces apoptosis and autophagy in human colorectal cancer cells through inhibition of PI3K/Akt/mTOR pathway. Oncol Rep 2016;36:3559-3567. 


\section{Cellular Physiology Cell Physiol Biochem 2017;43:1487-1502 \begin{tabular}{l|l|l} 
and Biochemistry 10.1159/000481971 & $\begin{array}{l}\text { C) } 2017 \text { The Author(s). Published by S. Karger AG, Basel } \\
\text { www.karger.com/cpb }\end{array}$
\end{tabular}

10 Zhao G, Shi A, Fan Z, Du Y: Salidroside inhibits the growth of human breast cancer in vitro and in vivo. Oncol Rep 2015;33:2553-2560.

11 Klionsky DJ, Abdelmohsen K, Abe A, Abedin MJ, Abeliovich H, Acevedo Arozena A, Adachi H, Adams CM, Adams PD, Adeli K, Adhihetty PJ, Adler SG, Agam G, Agarwal R, Aghi MK, Agnello M, Agostinis P, Aguilar PV, Aguirre-Ghiso J, Airoldi EM, Ait-Si-Ali S, Akematsu T, Akporiaye ET, Al-Rubeai M, Albaiceta GM, Albanese C, et al.: Guidelines for the use and interpretation of assays for monitoring autophagy (3rd edition). Autophagy 2016;12:1-222.

12 Yang ZJ, Chee CE, Huang S, Sinicrope FA: The role of autophagy in cancer: therapeutic implications. Mol Cancer Ther 2011;10:1533-1541.

-13 Chen Y, Henson ES, Xiao W, Huang D, McMillan-Ward EM, Israels SJ, Gibson SB: Tyrosine kinase receptor EGFR regulates the switch in cancer cells between cell survival and cell death induced by autophagy in hypoxia. Autophagy 2016;12:1029-1046.

14 Zhong JT, Yu J, Wang HJ, Shi Y, Zhao TS, He BX, Qiao B, Feng ZW: Effects of endoplasmic reticulum stress on the autophagy, apoptosis, and chemotherapy resistance of human breast cancer cells by regulating the PI3K/AKT/mTOR signaling pathway. Tumour Biol 2017;39:1010428317697562.

15 Martina JA, Diab HI, Li H, Puertollano R: Novel roles for the MiTF/TFE family of transcription factors in organelle biogenesis, nutrient sensing, and energy homeostasis. Cell Mol Life Sci 2014;71:2483-2497.

16 Giatromanolaki A, Sivridis E, Kalamida D, Koukourakis MI: Transcription Factor EB Expression in Early Breast Cancer Relates to Lysosomal/Autophagosomal Markers and Prognosis. Clin Breast Cancer 2017;17:e119-e125.

17 Giatromanolaki A, Kalamida D, Sivridis E, Karagounis IV, Gatter KC, Harris AL, Koukourakis MI: Increased expression of transcription factor EB (TFEB) is associated with autophagy, migratory phenotype and poor prognosis in non-small cell lung cancer. Lung Cancer 2015;90:98-105.

18 Klein K, Werner K, Teske C, Schenk M, Giese T, Weitz J, Welsch T: Role of TFEB-driven autophagy regulation in pancreatic cancer treatment. Int J Oncol 2016;49:164-172.

19 Perera RM, Stoykova S, Nicolay BN, Ross KN, Fitamant J, Boukhali M, Lengrand J, Deshpande V, Selig MK, Ferrone CR, Settleman J, Stephanopoulos G, Dyson NJ, Zoncu R, Ramaswamy S, Haas W, Bardeesy N: Transcriptional control of autophagy-lysosome function drives pancreatic cancer metabolism. Nature 2015;524:361-365.

20 Wei H, Wang C, Croce CM, Guan JL: p62/SQSTM1 synergizes with autophagy for tumor growth in vivo. Genes Dev 2014;28:1204-1216.

21 Liu W, Dai N, Wang Y, Xu C, Zhao H, Xia P, Gu J, Liu X, Bian J, Yuan Y, Zhu J, Liu Z: Role of autophagy in cadmium-induced apoptosis of primary rat osteoblasts. Sci Rep 2016;6:20404.

22 Li M, Pi H, Yang Z, Reiter RJ, Xu S, Chen X, Chen C, Zhang L, Yang M, Li Y, Guo P, Li G, Tu M, Tian L, Xie J, He M, Lu Y, Zhong M, Zhang Y, Yu Z, Zhou Z: Melatonin antagonizes cadmium-induced neurotoxicity by activating the transcription factor EB-dependent autophagy-lysosome machinery in mouse neuroblastoma cells. J Pineal Res 2016;61:353-369.

23 Yang M, Pi H, Li M, Xu S, Zhang L, Xie J, Tian L, Tu M, He M, Lu Y, Yu Z, Zhou Z: From the Cover: Autophagy Induction Contributes to Cadmium Toxicity in Mesenchymal Stem Cells via AMPK/FOXO3a/BECN1 Signaling. Toxicol Sci 2016;154:101-114.

24 Song P, Ye L, Fan J, Li Y, Zeng X, Wang Z, Wang S, Zhang G, Yang P, Cao Z, Ju D: Asparaginase induces apoptosis and cytoprotective autophagy in chronic myeloid leukemia cells. Oncotarget 2015;6:3861-3873.

-25 Fan TF, Bu LL, Wang WM, Ma SR, Liu JF, Deng WW, Mao L, Yu GT, Huang CF, Liu B, Zhang WF, Sun ZJ: Tumor growth suppression by inhibiting both autophagy and STAT3 signaling in HNSCC. Oncotarget 2015;6:43581-43593.

-26 Pi H, Xu S, Zhang L, Guo P, Li Y, Xie J, Tian L, He M, Lu Y, Li M, Zhang Y, Zhong M, Xiang Y, Deng L, Zhou Z, Yu Z: Dynamin 1-like-dependent mitochondrial fission initiates overactive mitophagy in the hepatotoxicity of cadmium. Autophagy 2013;9:1780-1800.

27 He ZJ, Zhu FY, Li SS, Zhong L, Tan HY, Wang K: Inhibiting ROS-NF-kappaB-dependent autophagy enhanced brazilin-induced apoptosis in head and neck squamous cell carcinoma. Food Chem Toxicol 2017;101:55-66.

28 Yin H, Yang X, Gu W, Liu Y, Li X, Huang X, Zhu X, Tao Y, Gou X, He W: HMGB1-mediated autophagy attenuates gemcitabine-induced apoptosis in bladder cancer cells involving JNK and ERK activation. Oncotarget 2017;10.18632/oncotarget.17796 


\section{Cellular Physiology Cell Physiol Biochem 2017;43:1487-1502 \begin{tabular}{l|l|l} 
and Biochemistry 10.1159/000481971 & $\begin{array}{l}\text { C } 2017 \text { The Author(s). Published by S. Karger AG, Basel } \\
\text { www.karger.com/cpb }\end{array}$ \\
\hline
\end{tabular}}

-29 Zhang D, Wang W, Sun X, Xu D, Wang C, Zhang Q, Wang H, Luo W, Chen Y, Chen H, Liu Z: AMPK regulates autophagy by phosphorylating BECN1 at threonine 388. Autophagy 2016;12:1447-1459.

30 Napolitano G, Ballabio A: TFEB at a glance. J Cell Sci 2016;129:2475-2481.

-31 Saftig P, Haas A: Turn up the lysosome. Nature Cell Biology 2016;18:1025-1027.

-32 Pi H, Li M, Tian L, Yang Z, Yu Z, Zhou Z: Enhancing lysosomal biogenesis and autophagic flux by activating the transcription factor EB protects against cadmium-induced neurotoxicity. Sci Rep 2017;7:43466.

-33 Kim YS, Lee HM, Kim JK, Yang CS, Kim TS, Jung M, Jin HS, Kim S, Jang J, Oh GT, Kim JM, Jo EK: PPAR-alpha Activation Mediates Innate Host Defense through Induction of TFEB and Lipid Catabolism. J Immunol 2017;198:3283-3295.

-34 Radogna F, Cerella C, Gaigneaux A, Christov C, Dicato M, Diederich M: Cell type-dependent ROS and mitophagy response leads to apoptosis or necroptosis in neuroblastoma. Oncogene 2016;35:3839-3853.

-35 Kaminskyy VO, Zhivotovsky B: Free radicals in cross talk between autophagy and apoptosis. Antioxid Redox Signal 2014;21:86-102.

-36 Yang C, Yang QO, Kong QJ, Yuan W, Ou Yang YP: Parthenolide Induces Reactive Oxygen Species-Mediated Autophagic Cell Death in Human Osteosarcoma Cells. Cell Physiol Biochem 2016;40:146-154.

-37 Stander XX, Stander BA, Joubert AM: Synergistic anticancer potential of dichloroacetate and estradiol analogue exerting their effect via ROS-JNK-Bcl-2-mediated signalling pathways. Cell Physiol Biochem 2015;35:1499-1526.

-38 Leddy LR, Holmes RE: Chondrosarcoma of bone. Cancer Treat Res 2014;162:117-130.

39 Zhang HT, Yang J, Liang GH, Gao XJ, Sang Y, Gui T, Liang ZJ, Tam MS, Zha ZG: Andrographolide Induces Cell Cycle Arrest and Apoptosis of Chondrosarcoma by Targeting TCF-1/SOX9 Axis. J Cell Biochem 2017;10.1002/jcb.26122

40 Hu X, Lin S, Yu D, Qiu S, Zhang X, Mei R: A preliminary study: the anti-proliferation effect of salidroside on different human cancer cell lines. Cell Biol Toxicol 2010;26:499-507.

-41 Reumann S, Shogren KL, Yaszemski MJ, Maran A: Inhibition of Autophagy Increases 2-MethoxyestradiolInduced Cytotoxicity in SW1353 Chondrosarcoma Cells. J Cell Biochem 2016;117:751-759.

-42 Bao X, Ren T, Huang Y, Sun K, Wang S, Liu K, Zheng B, Guo W: Knockdown of long non-coding RNA HOTAIR increases miR-454-3p by targeting Stat3 and Atg12 to inhibit chondrosarcoma growth. Cell Death \& Disease 2017;8:e2605.

43 Jiao G, Guo W, Ren T, Lu Q, Sun Y, Liang W, Ren C, Yang K, Sun K: BMPR2 inhibition induced apoptosis and autophagy via destabilization of XIAP in human chondrosarcoma cells. Cell Death \& Disease 2014;5:e1571.

44 Settembre C, Fraldi A, Medina DL, Ballabio A: Signals from the lysosome: a control centre for cellular clearance and energy metabolism. Nat Rev Mol Cell Biol 2013;14:283-296.

45 Martina JA, Chen Y, Gucek M, Puertollano R: MTORC1 functions as a transcriptional regulator of autophagy by preventing nuclear transport of TFEB. Autophagy 2012;8:903-914.

46 Pena-Llopis S, Vega-Rubin-de-Celis S, Schwartz JC, Wolff NC, Tran TA, Zou L, Xie XJ, Corey DR, Brugarolas J: Regulation of TFEB and V-ATPases by mTORC1. EMBO J 2011;30:3242-3258.

47 Roczniak-Ferguson A, Petit CS, Froehlich F, Qian S, Ky J, Angarola B, Walther TC, Ferguson SM: The transcription factor TFEB links mTORC1 signaling to transcriptional control of lysosome homeostasis. Sci Signal 2012;5:ra42.

48 Palmieri M, Pal R, Nelvagal HR, Lotfi P, Stinnett GR, Seymour ML, Chaudhury A, Bajaj L, Bondar VV, Bremner L, Saleem U, Tse DY, Sanagasetti D, Wu SM, Neilson JR, Pereira FA, Pautler RG, Rodney GG, Cooper JD, Sardiello M: mTORC1-independent TFEB activation via Akt inhibition promotes cellular clearance in neurodegenerative storage diseases. Nat Commun 2017;8:14338.

-49 Li X, Zhang X, Zheng L, Kou J, Zhong Z, Jiang Y, Wang W, Dong Z, Liu Z, Han X, Li J, Tian Y, Zhao Y, Yang L: Hypericin-mediated sonodynamic therapy induces autophagy and decreases lipids in THP-1 macrophage by promoting ROS-dependent nuclear translocation of TFEB. Cell Death \& Disease 2016;7:e2527. 